\title{
LA PROTECCIÓN DEL PACIENTE FRENTE A LOS DEBERES DE INFORMACIÓN Y SECRETO PROFESIONAL MÉDICO*
}

\author{
Mónica Lucía Fernández Muñoz"
}

Fecha de recibido: 20 de septiembre de 2014

Fecha de aprobado: 5 de noviembre de 2014

Artículo de reflexión

Forma de citación: Fernández, M. (2015). La protección del paciente frente a los deberes de información y secreto profesional médico. Revista Prolegómenos. Derechos y Valores, 18, 35, 153-168.

\section{Resumen}

Las normas de ética profesional cobraron un lugar preponderante en la valoración de la prestación médica, debido a la necesidad de incorporar criterios no comerciales en dicha valoración y evitar la deshumanización de la medicina. Tales normas, consagran ciertos deberes cuyo incumplimiento puede comprometer la responsabilidad civil, penal y disciplinaria del profesional de la medicina; algunos de estos, constituyen lo que se ha denominado como culpa médica en sentido deontológico, por contravenir deberes que integran el humanismo médico: la infracción al deber de informar y al deber de secreto profesional son algunos de ellos. Por lo tanto, el objeto de este artículo es subrayar el contenido y alcance de dichas obligaciones, a partir de algunas reflexiones que se soportan en los derechos español, francés e italiano.

\section{Palabras clave:}

Información, secreto profesional, paciente, obligación, responsabilidad médica.

\section{PATIENT PROTECTION FACING THE DUTIES OF INFORMATION AND OF MEDICAL PROFESSIONAL SECRECY}

\begin{abstract}
The rules of code of professional practice gained a preponderant place in the assessment of medical benefit, due to the need to incorporate non-commercial criteria in such assessment and avoid the dehumanization of medicine. Such rules enshrine certain duties whose failure may compromise the civil, criminal and disciplinary liability of physicians; some of these constitute what has been called medical guilt in a deontological way, for contravening duties that make
\end{abstract}

* Este artículo corresponde al resultado de una investigación adelantada en el marco del proyecto "La responsabilidad de las entidades de salud en Colombia", que se desarrolló dentro de la línea de investigación derecho privado, perteneciente al Grupo Investigaciones Sociojurídicas de la Facultad de Derecho de la Universidad Libre. El proyecto de investigación en mención ha sido financiado por la misma universidad.

** Ph.D. en Persona y Tutelas Jurídicas por la Scuola Superiore di Studi Universitari e di Perfezionamento Sant'Anna di Pisa (Italia). Investigadora visitante en la Universidad de París I Panthéon-Sorbonne (Francia). Abogada de la Universidad del Cauca. Especialista en Responsabilidad y Daño Resarcible de la Universidad Externado de Colombia y en Docencia Universitaria de la Universidad Militar Nueva Granada. Tratadista, conferencista, investigadora y docente universitaria. 
up the medical humanism: the breach of the duty to inform and of the duty of professional secrecy are some of them. Therefore, the purpose of this article is to highlight the content and scope of these obligations, from some reflections that are supported by the Spanish, French and Italian Law.

\title{
Keywords:
}

Information, professional secrecy, confidentiality, patient, physician, duty, obligation, medical liability.

\section{A PROTEÇAO DO PACIENTE EM FACE DOS DEVERES MÉDICOS DE INFORMAÇÃO E SEGREDO PROFISSIONAL}

\begin{abstract}
Resumo
As regras de ética profissional ganharam um lugar preponderante na valoração da prestação médica, por conta da necessidade de incorporar critérios não comerciais nesse âmbito e de evitar a desumanização da medicina. Tais regras incorporam certos deveres cujo cumprimento pode levar ao comprometimento da responsabilidade civil, penal e disciplinar do profissional da medicina. Alguns destes referem-se ao que tem se nomeado como "culpa médica" no sentido deontológico, por contravir deveres que integram o humanismo médico: as infrações ao dever de informar e ao dever de segredo profissional são alguns deles. Portanto, o intuito do presente artigo é colocar em destaque o conteúdo e alcance das referidas obrigações, partindo de algumas reflexões que se sustentam no direito espanhol, francês e italiano.
\end{abstract}

\section{Palavras-chave:}

Informação, segredo profissional, confidencialidade, paciente, médico, dever, obrigação, responsabilidade médica.

\section{INTRODUCCIÓN}

En materia de responsabilidad médica, tradicionalmente se ha hecho la distinción entre la culpa técnica médica y la culpa que resulta de la violación de un deber de humanismo médico (Kimmel-Alcover, 1996).

La culpa técnica, entendida como "la inobservancia de las técnicas médicas al momento de realización del acto médico"(Savatier, R.; Auby, R.; Savatier, J.; Pequignot, H. 1956, p.290) o también, "la violación de las reglas de la técnica profesional" (Marcos, 2003, p. 52), se caracteriza por requerir, para su reconocimiento, de una apreciación objetiva más que subjetiva, pues desde el punto de vista médico, la culpa profesional se establece en función de las normas médicas en vigor al momento de realización del acto. Estas normas médicas o científicas generalmente se invocan desde diversas denominaciones, entre ellas, "datos adquiridos por la ciencia" o "reglas del arte" (lex artis). Con razón se ha dicho queen contraste con las normas jurídicas, las normas científicas son de más difícil aprehensión por ser poco escritas, no permanentes por causa del progreso constante de las ciencias, y plurales, dada la existencia de variadas técnicas y corrientes científicas sobre la misma materia.

La culpa técnica concierne, entonces, al ejercicio del arte médico y corresponde a la inejecución o a la mala ejecución de la obligación de asistencia médica, por lo cual, esta clase de culpa puede 
ser variada y aludir a los distintos estadios de la acción médica, por ejemplo, a la actividad diagnóstica o a la ejecución práctica técnica del tratamiento.

Por otro lado, forman parte de la vulneración a un deber de humanismo médico, la negativa de consultar un especialista, aun cuando esta consulta sea reclamada por el mismo paciente; el hecho para el médico de cabecera de no aplicar el tratamiento propuesto por el especialista que él mismo consultó, pues según los usos profesionales, en caso de desacuerdo, el médico tratante debe avisar a la familia y hacer otra consulta a otro especialista o retirarse; la sustitución de un cirujano sin el consentimiento del paciente, fuera de todo evento de urgencia; emprender una intervención inútil o una intervención cuyos riesgos son desproporcionados en relación con el beneficio que se puede reportar con la misma; la violación del secreto profesional capaz de comprometer también la responsabilidad civil y finalmente, la falta al deber de información.

En este orden de ideas, la culpa de humanismo médico corresponde a la idea que en contrapartida de la confianza que el paciente pone en su médico, lo normal es que pueda esperar de él una información apropiada, clara y completa, además de la confidencialidad de los datos e información personal que le transmite como fruto de la relación que los une. Siendo considerados estos dos eventos, como aquellas causas que provocan más la atención dentro de las hipótesis de culpa por incumplimiento de un deber de humanismo médico, al punto que han sido catalogadas como verdaderas obligaciones de resultado (Jourdain, 1999), siendo estas dos hipótesis donde se centra la atención del presente estudio, entre otras razones, por el significativo impacto que generan en los derechos constitucionales fundamentales.

\section{A. Problema de investigación y enfoque metodológico}

El vínculo médico-paciente, de suyo controvertido, genera un sinnúmero de deberes recíprocos entre las partes en cuestión, siendo el deber de información y el deber de secreto profesional tal vez los de mayor significado, en razón a los efectos que estos ocasionan en la autonomía y en la intimidad del paciente.

La confianza en la cual se sustenta esta relación humana, tiene como origen "la razón, la intuición, la experiencia, el instinto" (Fernández, 2007, p. 99) y es un requisito indispensable para la eficacia de la asistencia médica; sin embargo, frente a fenómenos como la socialización de la medicina, la macromedicina, la medicina de grupo, etc. esta relación basada en la buena fe, tiende lastimosamente a debilitarse, por lo que se hace necesario su recuperación en la medida que constituye, como quedó anotado, el presupuesto sustancial del quehacer médico.

Por este motivo y debido a que en la práctica médica actual, el contenido del deber de información y del secreto profesional, no cuentan con suficiente regulación en Colombia, además de no existir una uniformidad de criterios que indique de manera clara a los profesionales de la salud los límites, excepciones y particularidades de estos deberes-con lo cual se desdibuja, como se señaló, los fines de la intervención médica-, el objetivo de esta investigación es revisar desde una perspectiva comparativa el contenido del deber de información y del secreto profesional con miras a aportar en la recuperación de la confianza como sustento básico de la relación médico-paciente y en la superación de la condición estructural de desequilibrio propio de dicho nexo, determinado por la asimetría en el conocimiento que caracteriza a sus protagonistas.

Para ello, desde una óptica teórica, en esta primera fase de la investigación se propende por la construcción del fundamento dogmático de estos dos deberes de índole moral, a través de los cuales se deben asegurar una práctica médica honesta y una conducta honorable por parte de los profesionales de la salud.

Así pues, teniendo en cuenta el enfoque teórico de la investigación, la metodología que se 
empleó se apoyó en un tratamiento esencialmente cualitativo, donde se aplicaron el análisis, la síntesis, la inducción y la deducción como métodos generales de investigación científica, combinados con otros procedimientos como la observación, la comparación, la abstracción y la conceptualización, como métodos particulares, con un alcance exploratorio, descriptivo, analítico, explicativo y comparativo.

\section{B. Resultados}

\section{I.El deber de información como piedra angular del consentimiento en la relación médico-paciente}

\section{Fundamento del deber de información}

Es de recordar que la finalidad de la información es proporcionar, a quien es el titular del derecho, los medios para decidir de forma adecuada y según considere lo más conveniente a sus intereses (Bello, 2011). Así, el deber de información encuentra su soporte en la libertad del paciente (Lorenzetti, 2005), por ello se afirma que la obligación del galeno de no actuar sobre el cuerpo del paciente, sin que este haya expresado libremente su consentimiento al respecto, se acompaña del deber de informar que tiene el profesional. Esto es, para dar la aprobación al acto médico y así legitimarlo, se requiere que el paciente haya sido informado, pudiendo contar con los elementos de juicio suficientes que le permitan decidir con libertad.

Lo que en últimas se persigue con este deber de información es que, con fundamento dogmático en el principio de buena fe, el profesional médico, atenúe de alguna manera la desigualdad que en términos de competencia técnico-científica existe entre las partes de esta relación jurídica (Fresa, 2008; Jaramillo, 2008). Y así lo confirma la propia casación italiana, en sentencia 10014 del 25 de noviembre de 1994, cuando manifiesta que

[...]el deber de informar al paciente sobre la naturaleza de la intervención médica y/o quirúrgica, sobre la portada y extensión y sus riesgos, sobre los resultados obtenibles y sobre las posibles consecuencias negativas, que pesa sobre el médico en general, se deduce de las normas constitucionales y del comportamiento según la buena fe a que son obligadas las partes durante el desarrollo de las tratativas y en la formación del contrato.

El deber de informar al paciente tiene sustento en el principio de la libertad personal, el cual se expresa en el derecho a salvaguardar la propia integridad psicofísica y en la autodeterminación en cuanto a las decisiones que se asocian con la propia salud. De este modo, el deber de información es vital para la protección de los citados derechos. Sin la previa información, no es posible hablar de consentimiento "competente" o "consciente" (Fresa, 2008).

Así, el deber de información, entendido como presupuesto necesario para el consentimiento o asentimiento por parte del paciente (Lorenzetti, 2005) y para algunos, como uno de los deberes accesorios, secundarios o instrumentales más relevantes en la esfera de la relación médico-paciente (Jaramillo, 2008), consiste en la obligación del médico de hacer saber al paciente cuál es su estado, el diagnóstico de su enfermedad, el tratamiento a seguir, así como los riesgos inherentes y los efectos de dicho tratamiento (Fernández, 2002). Es decir, el deber de información se extiende al diagnóstico, pronóstico, las alternativas de tratamiento, las consecuencias sobre la vida personal, profesional, de relación en general y los riesgos previsibles. En este orden de ideas, el paciente debe ser informado, por ejemplo, de la evolución previsible de su estado de salud, la naturaleza exacta del acto médico que va a practicarse, el objetivo de la intervención y los medios técnicos existentes para llevarla a cabo, las consecuencias posibles, la duración de la hospitalización, las precauciones que debe tomar y el tiempo de convalecencia.

Para ello, es menester que el paciente reciba una visión completa de la situación en la que se encuentra su salud y aquí no se desconoce el importante papel que ocupa el profesional de la 
medicina, cuya asistencia moral y participación, adquieren el mismo valor que su habilidad técnica (Bilancetti, 2003).

En cuanto al derecho internacional, este derecho del paciente a ser informado tiene su fundamento normativo en la Declaración Universal de Derechos Humanos de 1948 y en el Pacto Internacional de Derechos Civiles y Políticos de Nueva York de 1966. Para el caso específico de Colombia, la Corte Constitucional en reiteradas decisiones, como las tomadas en los fallos T-401/1994, T-477/1995, T-551/1999 y T-692/1999, declaró que este deber de información es de raigambre constitucional al ser una emanación de los derechos fundamentales a la dignidad humana, la autonomía personal y el libre desarrollo de la personalidad.

El incumplimiento de este deber compromete la responsabilidad médica, pues la omisión de una correcta información vicia el contrato por violación de una de las obligaciones que recaen en el médico y hace surgir el derecho al resarcimiento del daño, claro está, se ha dicho, siempre que haya una relación de causalidad entre la falta de información y el daño causado, es decir, siempre que se pruebe que el daño proviene de un riesgo que debió advertirse; sin embargo, teniendo en cuenta que la lesión puede provenir de otra causa, en este especial evento, cobra significado la aplicación de teorías como la pérdida de oportunidad.

No obstante, respecto al surgimiento del deber de reparación como consecuencia del incumplimiento de este deber, hay una visión contraria, que es por ejemplo, la que comparte la Corte de Casación francesa, según la cual, el defecto de información constituye de por sí un perjuicio "autónomo" (Truchet, 2013), que debe indemnizarse en el marco de la responsabilidad extracontractual, en la medida que la información se concibe como la condición cardinal del consentimiento. En similar sentido, Ghersi, Wingarten, Iglesias, Ferrari y Waisman (1998) manifiestan que la ausencia o el incumplimiento del deber de información es de por sí violatorio de tal obligación, lo que explica que su omisión genere responsabilidad en forma "autónoma".

Con respecto a esta oposición, referida a la calificación de la obligación de información como "accesoria o instrumental" o como obligación "autónoma" en cuanto al deber de prestación del servicio médico, Raffaella-de Matteis (2007), concluye que dicha contradicción puede explicarse en tanto que se estiman distintos los dos planos de relevancia del consentimiento del paciente, esto es, por un lado, como un acto de ejercicio del-derecho a la autodeterminación terapéutica $y$, por otro, como elemento crucial del acuerdo contractual; empero, resaltando el relieve dado al deber de información en cuanto expresión de la protección constitucional que debe ser reconocida al derecho de autodeterminación terapéutica, la autora afirma que el deber de información, resulta ser atraído a la compleja estructura de la relación obligatoria, colocándose "al lado" del núcleo central constituido por la obligación de prestación principal y no como una obligación meramente "accesoria o instrumental" respecto a la misma, es decir, apreciándose como obligación "autónoma", cuyo incumplimiento hace manar la responsabilidad del médico.

La obligación de información debe ser anterior y posterior al acto médico (Dorsner-Dolivet, 2006), garantizándose de este modo la exigencia de una información continuada, a lo largo de toda la atención, mientras el enfermo está bajo el cuidado del profesional de la salud (Martín, 1998). En otras palabras, una información que atendiendo al carácter de tracto sucesivo de la prestación de asistencia médica (Sánchez, 1998), está destinada a permitir que el paciente otorgue su anuencia y a asegurar el seguimiento del acto realizado dando consejos e indicaciones al paciente. Sin embargo, debe considerarse que este deber de información a cargo del médico se delimita de acuerdo con la individualidad del paciente en concreto (Martín, 1998). En efecto, el profesional debe tener en cuenta aspectos personales subjetivos y objetivos concurrentes del paciente, tales como su nivel cultural, su edad, su situación familiar, personal y además, el grado 
de precisión que se exija dependiendo de si se está o no ante una circunstancia de urgencia.

\section{Características de la figura}

En lo relativo al contenido o características de este deber, legislación, doctrina y jurisprudencia de varios países se han encargado de desarrollar estos aspectos, afirmando, por ejemplo, que la información debe ser "adecuada": proporcionada a tiempo y de manera comprensible. Debe tratarse de una información "equilibrada, razonable y suficiente" (Jaramillo, 2008). Una información objetiva, veraz, completa, asequible y que suministre personal y directamente el médico. El Código de Salud Pública en Francia enuncia, por ejemplo, que esta información debe ser "leal, clara y apropiada" e igualmente, desde el año 1961, la Corte de Casación francesa aseveró que la información debía ser "simple y aproximativa, pero inteligible y leal".

A este respecto, nuestro Consejo de Estado (2002), con clara influencia del derecho francés, expresó que teniendo en cuenta que la relación médico-paciente se edifica sobre dos pilares: la capacidad técnica del profesional sanitario y el consentimiento idóneo e informado, para que exista el segundo pilar, se debe considerar que la información que se brinde al paciente debe ser "leal, clara y apropiada", además, "adecuada, clara, completa y explicada al paciente". Así, el galeno debe esforzarse por superar el desequilibrio informativo y lograr que el paciente comprenda, asimile lo que se le transmitió, para ello tendrá entonces que utilizar un lenguaje corriente, llano, sencillo, inteligible, pues como bien se ha dicho "de nada sirve informar, si lo informado no es entendido" (Jaramillo, 2008, p.230).

Para la doctrina italiana (Farneti et al., 2007), la conversación directa puede apoyarse en herramientas y documentación, aportando así a una educación sanitaria, que permita la comprensión y gestión del caso clínico en concreto, en modo tal que suscite en el paciente un interés responsable por su situación clínica, más allá del interés que intuitivamente tenga, pues lo que interesa no es que el paciente sepa mucho, sino que sepa "bien" y se logre persuadirlo o inducirlo a un comportamiento proactivo y responsable.

En cuanto a la información de los riesgos, Francia ha evolucionado, pues en sus orígenes la Corte de Casación consideraba que el médico profesional de la salud debía informar solo los riesgos normalmente previsibles, pero no los excepcionales, de la intervención o tratamiento proyectado, por ejemplo, el médico estaba en la obligación de informar el riesgo de parálisis del nervio ciático consecutiva a una operación con destino a corregir luxaciones congénitas de la cadera (riesgo previsible), pero no el riesgo de parálisis definitiva del nervio ocular como consecuencia resultado de una anestesia o bloqueo, por vía orbitaria, del nervio maxilar superior (riesgo excepcional), salvo que se tratara de una cirugía estética, pues aquí el médico sí tendría la obligación de informar revelar tanto los riesgos previsibles como los excepcionales.

Con posterioridad a este periodo, la jurisprudencia francesa abandonó esta distinción entre riesgos normalmente previsibles y riesgos excepcionales, para lo cual adoptó el criterio cualitativo sobre la "gravedad" del riesgo. Así, varios fallos de la casación francesa del año 1998 anunciaron que el médico estaba obligado a dar una información "leal, clara y apropiada sobre los riesgos graves" y no estaba dispensado de esta obligación por el hecho de que dichos "riesgos se realizaran solo excepcionalmente". El concepto de riesgo "grave" se definió como "aquel de tal naturaleza que conlleve consecuencias mortales, invalidantes o incluso estéticas graves, teniendo en cuenta sus repercusiones psicológicas y sociales" (DorsnerDolivet, 2006). Para establecer cuándo un riesgo es "grave" se señaló, así mismo, que debía repararse en "aquel susceptible de influenciar la decisión del paciente" (Welsch, 2003, p. 78) $e$ igualmente se definieron como tales aquellos que lograban "poner en juego el pronóstico vital o que alteraban una función vital" (Sargos, 2002, p. 378).

De acuerdo con lo anterior, en Francia se han considerado como riesgos graves cuya no información genera responsabilidad, entre otros: los 
riesgos de infección nosocomial con ocasión de una intervención quirúrgica en la rodilla o las eventuales consecuencias que puede traer consigo una infección posoperatoria de catarata, como la enucleación del globo ocular, complicación rara pero no excepcional, omisiones de información que privan al paciente de la posibilidad de decidir con claridad entre hacerse operar de inmediato o no.

Por último, la ley Kouchner de 2002, que erigió la información médica al rango de derecho subjetivo del paciente (Hocquet-Berg\&Py, 2006), precisa el deber de advertir los "riesgos frecuentes o graves normalmente previsibles" (ley Kouchner 2002), lo que deja entrever la intención del legislador francés de que el médico informe los riesgos graves cuando estos sean frecuentes y previsibles desde un punto de vista estadístico, continuando de esta manera con el criterio cuantitativo adoptado con anterioridad a esta ley. Por esta ambigüedad de la norma, la misma Corte de Casación estimó que en cuanto a la previsibilidad del riesgo, el contenido de la información debía extenderse a los "riesgos conocidos" según los datos adquiridos de la ciencia a la fecha del acto médico.

En tal sentido, la información no será adivinatoria, sino que implicará aquello que se sabe y llegará hasta donde se conoce (Mosset\&Piedecasas, 2011). En el evento específico se trató de una paciente que como efecto de un lifting frontal por vía endoscópica presentó alopecia y demandó la responsabilidad del médico por no haberle informado de la existencia de ese riesgo. Aunque el cirujano estético es obligado a dar una información exhaustiva de los riesgos e inconvenientes que se ligan a su intervención, en este caso fue exonerado, pues la obligación, como lo dijo la Corte, se extendía a los riesgos conocidos a la fecha del acto médico y este no era el caso de acuerdo con el dictamen pericial que se llevó a cabo en este proceso.

Así pues, en el entendido de que solo el riesgo conocido es el que debe informarse, es indispensable tener en cuenta que debe tratarse de un riesgo previsible, pues los riesgos imprevisibles escapan al deber de información. De esta forma lo consagró la Corte de Casación francesa en un caso fallado en el 2004, en el cual la administración de un antibiótico durante una intervención quirúrgica de la rodilla, produjo un shock anafiláctico que acarreó anoxia cerebral y consecuente coma. El paciente con importantes secuelas, demandó la reparación de los daños por no habérsele informado de los riesgos de alergia a este antibiótico. La Corte exoneró de responsabilidad al profesional al considerar que si bien el riesgo de alergia al antibiótico administrado era "conocido", su realización era "imprevisible" en el caso concreto de ese paciente, al cual se le habían hecho todos los exámenes preoperatorios y preanestésicos y no tenía antecedentes alérgicos. Por ende, se concluyó que los médicos no cometieron culpa al no informar al paciente sobre esta contingencia.

A este respecto, es relevante indicar que existe una diferencia tajante entre previsibilidad y frecuencia del riesgo. En efecto, la doctrina española (Galán, 2011) señala que para la determinación del riesgo previsible (o típico), no deben estimarse criterios estadísticos o porcentuales, pues el hecho de que ciertos sucesos se produzcan de forma previsible no implica que sucedan con una frecuencia numérica. El Tribunal Superior español, por ejemplo, en sentencia del 30 junio de 2009, subrayó que no podía considerarse como "imprevisible" una complicación descrita en la literatura científica con una estimación de "frecuencia" del 3,5\%, ya que la circunstancia de que el riesgo de una intervención sea poco probable no exime de informar al paciente del mismo si es conocido según el estado de la ciencia en la época de la intervención.

Así las cosas, la previsibilidad no tiene nada que ver con la frecuencia, pues poco importa la frecuencia a efectos de la información, es decir, un médico no puede justificar su omisión o ineficiencia en el cumplimiento de su deber de información, aduciendo que el riesgo es poco frecuente o imprevisible.

Para el caso específico de Colombia, los artículos 15 y 16 de la ley 23/1981, en concordancia con 
los artículos 9 y 10 de su decreto reglamentario 3380/1981, disponen que el médico está obligado a informar sobre los riesgos previstos teniendo en cuenta el estado y avance de la ciencia médica en un momento determinado y que el médico no puede exponer a su paciente a riesgos que no se justifiquen. De estas normas se desprende que el galeno compromete su responsabilidad no solo cuando incumple su deber de notificar todos los riesgos previstos, es decir, los efectos adversos que pueden llegar a presentarse como consecuencia del tratamiento o procedimiento médico, sino también, cuando somete al paciente a riesgos injustificados, esto es, aquellos que no corresponden a las condiciones clínico-patológicas del paciente.

En este orden de ideas, de acuerdo con nuestro sistema jurídico, el médico responde cuando incumple su deber de informar todos los riesgos connaturales, inherentes o previstos por la ciencia médica, igualmente responde cuando incrementa de modo innecesario los riesgos de las prácticas médicas (López, 2007). Así pues, cuando el paciente es afectado por otros eventos de carácter excepcional y fortuito(de imposible o difícil previsión), no cabe imputar responsabilidad alguna al médico, pues respecto a este tipo de riesgos, también llamados riesgos atípicos (Bermúdez, 2000), no existe obligación de advertencia alguna, opera un rompimiento del nexo de causalidad, considerándose un caso fortuito.

Como puede observarse, es desde el panorama de la obligación de información y en consecuencia de la responsabilidad por culpa, que el paciente viene a protegerse frente a los eventos de ocurrencia de un riesgo médico. Así, cuando el paciente se somete a un tratamiento o a una intervención quirúrgica debe ser informado de los riesgos que asume y que son connaturales, inherentes o previstos por la ciencia médica. Una vez informado, el paciente decide si se somete o no al tratamiento o intervención y si lo hace, desde ese momento debe, en principio, soportar ese riesgo.

\section{Excepciones al deber de informar}

Existen ciertas situaciones respecto de las cuales la doctrina y la jurisprudencia de diversas regiones concuerdan con que estas permiten exonerar al profesional de su obligación de informar. Estas son:

1. Cuando el destinatario de la información es otro profesional médico que conoce de la misma especialidad (Jaramillo, 2008). En efecto, en este caso se puede considerar que ambas partes de la relación jurídica, se encuentran en igualdad de condiciones, superándose la desigualdad informativa y de conocimientos que se espera vencer a través de la consagración del deber de información. Se trata de dos personas, médico y paciente, que están en el mismo nivel de conocimiento, por lo tanto, dadas las específicas características, podría pensarse en una exoneración del deber de información de quien actúa como médico tratante.

2. Cuando el paciente ha sido sometido de manera reiterada al mismo tratamiento del cual ya ha sido amplia y suficientemente informado (Jaramillo, 2008).

3. En caso de imposibilidad de obtener el consentimiento (por ejemplo, por la fragilidad psicológica del paciente). A este respecto, en Francia, el propio Código de Salud Pública autoriza al médico, en interés del paciente y por razones que él debe apreciar en consciencia, a tener al paciente ignorante respecto de un diagnóstico grave (Berthiau, 2007). Se afirma que si la información puede afectar al paciente, principalmente por los efectos psicológicos desastrosos que traería la revelación del dictamen, es preferible limitar dicha obligación. Según Berthiau (2007), la imposibilidad de informar a la cual hace referencia la norma (art. L 1111-2/3 CSP), puede interpretarse, según los términos del código de deontología, como un inconveniente que se liga al interés absoluto del paciente. 
El derecho italiano, por su parte, considera que por ejemplo, en los casos de pacientes oncológicos, especialmente en aquellos sujetos a experimentación clínica de nuevos fármacos o métodos, ningún médico que sea humanamente sensible ilustraría en modo completo al paciente sobre su situación clínica, pues esto equivaldría a una inútil crueldad que lo único que podría causar sería estrés y ansiedad. En consecuencia, si bien lo deseable es obtener una relación sincera y honesta con el paciente, no es así para todos los ambientes y ni siquiera en igual medida para todos los países de diferente cultura (Fiori, 1999), así pues, se concluye que la información al paciente es un proceso continuo que puede ejecutarse por etapas, con prudencia y delicadeza.

Como puede observarse, se trata de excepciones a la obligación de información; sin embargo, debe tenerse claro que en ningún caso se accede a que el médico se descargue totalmente de su obligación de obtener el consentimiento del paciente. Es decir, se admite que el cirujano suministre informaciones discretas, pero esta posibilidad no implica el silencio completo, permitiéndole operar sin el beneplácito del paciente, pues siempre deben respetarse los criterios mínimos para poder hablar de una aprobación libre de vicios.

Incluso, debe tenerse en cuenta que, salvo que la urgencia no lo conceda, en caso de estar presentes familiares o personas allegadas es a estos a quienes corresponde el derecho de decidir. A este respecto se ha dicho incluso que los lazos directos familiares pueden relegarse, en ciertas situaciones, a favor de quien tiene una relación de hecho más estrecha con el enfermo (Fernández, 2002).

4. El rechazo del paciente a ser informado (Welsch, 2003), es otro de los eventos donde también opera la excepción al deber de información; es decir, cuando el mismo paciente por voluntad propia, previa y reflexiva, manifiesta su deseo de renunciar a su derecho a ser informado. Aquí surge la obligación para el médico de respetar la voluntad del paciente que desea ignorar el diagnóstico o pronóstico de su enfermedad, como muestra del respeto a su derecho a la libertad y a la autodeterminación. Sin embargo, sobre este aspecto, el Código de Salud Pública en Francia tiene una excepción: cuando terceras personas puedan quedar expuestas a un riesgo de contagio.

En estos eventos prima el interés general. Piénsese, por ejemplo, en el caso de un enfermo infectado con el virus de inmunodeficiencia humana, pues aquí a pesar de que el paciente exprese su clara intención de no saber nada sobre su estado de salud, aun así el médico tendrá que informar, pues la salud pública estaría de por medio.

\section{El secreto profesional médico y su incidencia en la protección de la esfera privada del paciente}

\section{Fundamento del deber de secreto profesional médico}

Una aplicación específica del deber general de guardar secreto profesional es la obligación en virtud de la cual el médico mantiene reserva en cuanto a la enfermedad del paciente (Jaramillo, 2008). Obligación esta que no cesa siquiera con la muerte de este. Ya en Francia, el médico personal del expresidente Françoise Mitterrand fue condenado disciplinaria, civil y penalmente, por revelar después del fallecimiento de su paciente, la evolución del estado de salud del mismo, pues se consideró que este deber no podía lesionarse, ni siquiera en este caso, donde al parecer se pretendía hacer una contribución a la historia (Truchet, 2013).

Esta obligación de carácter accesorio respecto a la principal de asistencia médica, encuentra su precedente en el juramento hipocrático, adaptado por la Declaración de Ginebra de 1948, desde donde se importó a los códigos deontológicos de muchos países, que lo han concebido como norma deontológica de rigurosa observancia en razón a su incidencia directa sobre la intimidad de los pacientes. Se trata de una obligación moral, que se conecta estrechamente con la 
ética profesional, donde el secreto profesional y el derecho a la intimidad se vinculan, ya que "desde el momento en que se adquiere tal secreto o confidencia, simultáneamente, se viene a producir una ruptura, aún parcial, de la intimidad personal" (Mémeteau, 2010).

En verdad, este deber reviste una innegable importancia debido a la protección del derecho a la intimidad que conlleva la relación médicopaciente, como derecho fundamental, que para el caso de Colombia se consagró en el artículo 15 de la Constitución Nacional. Existe, en efecto, un estrecho lazo entre el derecho a la intimidad y el deber que le asiste al profesional de guardar el secreto médico (Sánchez, 1998). Con el secreto se pretende la salvaguardia de la intimidad como interés independiente de la protección de la salud del paciente. Así, teniendo en cuenta que el secreto profesional justifica, por causa de una actividad profesional, la sustracción al conocimiento ajeno de datos obtenidos que conciernen a la vida privada de las personas, este adquiere especial relevancia en el caso de la reserva médica, debido a la particularidad de la relación médico-paciente que establece entre los actores un vínculo que se basa en la confianza y discreción, que facilita la revelación de datos relativos a aspectos íntimos del paciente.

Por su innegable relevancia, concretamente en Colombia, el secreto profesional se eleva a rango constitucional, el artículo 74 de la Carta Política lo garantiza cuando instituye que "el secreto profesional es inviolable"; igualmente, el secreto médico está regulado en la ley 23/1981 en materia de ética médica, donde su artículo 2 concerniente al juramento médico, señala: "Prometo solemnemente: [...] guardar y respetar los secretos a mí confiados", el artículo 37 por su parte, declara que se entenderá por secreto profesional médico "aquello que no es ético o lícito revelar sin justa causa" y sigue, "El médico está obligado a guardar el secreto profesional en todo aquello que por razón del ejercicio de su profesión haya visto, oído o comprendido, salvo en los casos contemplados por las disposiciones legales".

A pesar de estas normas, podría afirmarse que en nuestro país este deber no está bastante regulado, aunque si bien es cierto, a este tenor no podrían proponerse reglas generales, pues en la práctica no podrían ser aplicables, en su generalidad, al total de los casos. Cuando el médico actúa como perito, por ejemplo, muchas veces resulta difícil determinar el contenido de lo que puede develar, sin transgredir esta obligación. Piénsese en la entidad de la enfermedad implicada, pues podría requerirse más cautela en la revelación del secreto cuando se trata de un paciente infectado por sida.

Ahora bien, la doctrina española (Blázquez \& Molinos, 1997) refiere que en la peritación en materia penal sobre lesiones personales, podría constituir una violación del secreto profesional el hecho de revelar partes innecesarias o no relevantes en el juicio, que no suponen una alteración de la verdad pero, al contrario, sí provocan una lesión al patrimonio psíquico y moral de la persona que ha sido explorada en forma confidencial.

Por su lado, el derecho francés, juzga que el perito médico no puede deducir de la misión que se le confió un derecho de acceso directo a la historia clínica, en estos eventos el experto, siendo un técnico que colabora ocasionalmente al servicio de la justicia, debe solicitar una autorización escrita de la persona interesada (Welsch, 2003).

Este deber de secreto profesional es objeto de diversas controversias que se enlazan con su cumplimiento efectivo, debido no solo al ejercicio actual de la medicina que implica que el paciente sea atendido por varios profesionales de la salud (médicos, enfermeras, auxiliares, etc.), lo cual conlleva que sean varias las personas que en últimas tienen acceso a los datos personales del paciente, sino también, debido a las nuevas tecnologías, que provocan un manejo informatizado de los datos de la salud del enfermo (Blázquez \& Molinos, 1997), en principio, porque los datos que reposan, por ejemplo, en historias clínicas electrónicas, pueden ser objeto de consulta de personal médico autorizado o porque se viola la seguridad de las aplicaciones. En muchos casos, resulta difícil estimar a qué nivel y porqué circunstancia se vulnera el secreto profesional. Por lo anterior, surgen dos conceptos-vinculados al ejercicio de la medicina en equipo o medicina 
socializada (Criado, 1999)-: (i) secreto médico compartido: reserva que comparten todas las personas que asisten al paciente (médico tratante, médicos en formación, practicantes y residentes); y(ii) secreto médico derivado: le compete al personal no sanitario, que indirectamente en razón de su trabajo administrativo y de gestión, llega a tener acceso a la información(secretarias, personal administrativo, entre otros).

\section{Extensión del deber de secreto médico}

Es necesario diferenciar los eventos que comprometen la responsabilidad médica por incumplimiento de este deber de secreto profesional, de aquellos donde la revelación de la información no origina responsabilidad por no formar parte de dicho secreto.

En este punto la doctrina se preocupa por definir qué datos deben entenderse como privados, respecto de los cuales el médico ha de guardar silencio. La determinación de este criterio genera distintas controversias tendientes a apreciar el carácter secreto de un hecho, teniéndose como pauta general que

[...]el secreto médico debe extenderse a una serie de datos privados que deben ser considerados como íntimos, porque afectan a la intimidad del paciente al incidir sobre su salud y porque existe el deseo de que permanezcan ocultos, en atención a su voluntad o al sentir social (Sánchez, 1998, p. 169).

En Colombia la ley 23/1981 en su artículo 37 expresa:

Entiéndase por secreto profesional médico aquello que no es ético ni lícito revelar sin justa causa. El médico está obligado a guardar el secreto profesional en todo aquello que por razón del ejercicio de su profesión haya visto, oído o comprendido, salvo en los casos contemplados por disposiciones legales.

El médico debe entonces, guardar secreto de todo lo que el paciente le confíe de manera espontánea o inducida y de todos los hechos que involuntariamente haya advertido o constatado gracias a su ejercicio profesional, aunque se desconozcan por parte del paciente (Fernández, 2002; Jaramillo, 2008; Sánchez, 1998). Este último evento es el que diferencia al secreto médico del secreto profesional en general y se explica por la desigualdad existente entre las partes desde el punto de vista intelectual, pues es la ignorancia del paciente en cuanto a su estado de salud, lo que favorece que el médico pueda saber sobre hechos incluso desconocidos para él.

Así pues, se afirma, como principio general, que el secreto médico se extiende a la enfermedad misma, a las exploraciones, pruebas, diagnóstico, pronóstico, tratamiento, hospitalización e incluso a la historia clínica, cuya custodia debe garantizarse (Sánchez, 1998). Aunque hay excepciones. Y se circunscriben al imperativo legal; la existencia de una orden de autoridad judicial; el consentimiento del paciente; la existencia de interés científico y la concurrencia de un interés por parte del médico. Veamos.

1. La obligación para el médico de comparecer ante los jueces en calidad de testigo o perito y la obligación de denunciar delitos, relajan el cumplimiento del deber de secreto médico. La exigencia de ley, entonces, hace que el médico revele su secreto.

En este aspecto, el derecho francés consagra una variedad de casos donde es la norma la que permite el descubrimiento de las informaciones o constataciones que el galeno obtuvo de su paciente. Así, deben declararse el hecho del nacimiento y la muerte, las enfermedades contagiosas y venéreas, los certificados de internación para los enfermos mentales patológicos, los alcohólicos peligrosos, los incapaces mayores, los accidentes de trabajo, las enfermedades profesionales y las pensiones militares y civiles (Welsch, 2003).

En lo tocante a la actuación del profesional sanitario como testigo o perito, se ha aclarado que este debe actuar con cautela y discreción, apreciando si debe reservarse ciertos datos, pues si bien existe el compromiso de colaborar con la justicia, puede haber circunstancias donde no hay claridad en cuanto a los beneficios que pueda recibir el paciente con la revelación del 
secreto. Para la doctrina española (Lachica, 2002; Sánchez, 1998), el médico debe sopesar y seleccionar qué datos resultan en verdad útiles a la justicia y callar aquellos que sean innecesarios y cuya develación constituya un atentado a la intimidad de su paciente.

Por otra parte, frente a los casos de conflicto entre el interés público y el interés particular, es indiscutible la delicada situación en que se encuentra el profesional, debiéndose aquí analizar el caso concreto, a fin de determinar si hay o no necesidad de revelar el secreto médico para salvaguardar la salud pública. Piénsese, por ejemplo, en el evento de un enfermo infectado por el virus del sida que continúa manteniendo prácticas de riesgo sin las debidas precauciones; aquí, se reconoce la primacía del interés general, la cual puede limitar la obligación de secreto médico (Fernández, 2002; Sánchez, 1998).

En Colombia, el evento específico de los pacientes con sida se regula por un conjunto de normas, entre estas, el decreto 1543/1997, que dispone en su artículo 34 que por razones de carácter sanitario, el médico tratante, en armonía con los consejos que dicta la prudencia, puede hacer la revelación del secreto profesional a las siguientes personas: (i) al infectado, en aquello que estrictamente le concierne y convenga; (ii) a los familiares del afectado, si la revelación es útil al tratamiento; (iii) a los responsables del enfermo, cuando sean menores de edad o personas mentalmente incapaces; (iv) a los interesados por considerar que se encuentran en peligro de infección, al cónyuge, compañero permanente, pareja sexual o a su descendencia; y $(v)$ a las autoridades judiciales o de salud competentes en los casos previstos por la ley. Esta revelación debe hacerse previa consejería para los literales (i), (ii), (iii) y (iv).

2. La existencia de una orden de autoridad judicial que decrete la intervención de una historia clínica dentro de un proceso, es también una excepción a la obligación de secreto médico.

En un evento como este, relativo a la investigación de un delito, el Tribunal Constitucional español apunta que la intervención sobre la historia clínica, no produce vulneración del derecho a la intimidad, pues

[...]a pesar de que la historia clínica constituye un documento que el interesado tiene derecho a sustraer del conocimiento de los demás, estando el médico que la elaboró vinculado a su secreto profesional, no hay derechos ilimitados y la intimidad no es una excepción. En consecuencia, puede verse restringida por las actuaciones de la justicia como, por ejemplo, por mandato judicial, sin que sea posible predicar su carácter ilegítimo (Sánchez, 1998, p.178).

3. Previo el reconocimiento del carácter relativo de la reserva profesional, se afirma la validez del consentimiento del paciente para excluir al médico de esta su obligación. Empero, tal reconocimiento con carácter general de la eficacia del consentimiento, plantea algunas excepciones, la primera de ellas tiene que ver con la posible producción de un perjuicio a terceras personas o al interés público (Fernández, 2002); en ambos casos la aprobación dada por el paciente para revelar el secreto médico se considera inválida.

La segunda excepción se relaciona con los efectos de la autorización, es decir, advertir si dicha aquiescencia comporta, por sí misma, una obligación del médico para develar el secreto. En lo que atañe a este punto, se ha concluido que es una simple facultad, esto es, el profesional será libre o no de revelar el secreto; de este modo, la anuencia del paciente se erige como condición imprescindible, pero no suficiente para el levantamiento del secreto médico; sin embargo, no debe olvidarse que la obligación de revelación siempre existirá cuando estén de por medio intereses de terceros o el orden público.

La última excepción tiene que ver con la extensión del consentimiento: si este alcanza solo a los hechos dados a conocer por el paciente, o si por el contrario, se extiende a las constataciones involuntarias obtenidas por el médico; coligiéndose que la autorización dada por el paciente 
solo va hasta los datos que él conoce, pues las constataciones del médico afectan el derecho a la intimidad de su paciente y por lo tanto, una divulgación sin su asenso puede vulnerarla.

4. Cuando la información se emplea en pro de la ciencia, con carácter pedagógico o académico, se considera que se está ante otro evento de limitación o inaplicabilidad del secreto médico. Sin embargo, en este caso se aboga por el sumo cuidado con que debe hacerse la revelación del secreto, el cual debe garantizar el anonimato del paciente (Jaramillo, 2008). En efecto, la divulgación del secreto médico se justifica en atención al interés supremo representado por el progreso científico; no obstante, a pesar de que concurra un interés científico, es obligatorio contar con el beneplácito del paciente y una vez se alcance dicha autorización, debe evitarse la identificación de este, so pena de que se declare la responsabilidad (Sánchez, 1998), como ocurrió en un caso fallado por el Consejo de Estado francés que sancionó disciplinariamente a un médico, quien para una encuesta sobre la hipnosis difundió la fotografía de una paciente tomada en su consultorio, incluso con la aquiescencia de la interesada, ya que la revelación de la identidad de dicha paciente formaba parte de las informaciones garantizadas por el secreto médico (Welsch, 2003). Un hecho similar falló el Tribunal Supremo español, que condenó a un galeno a pagar dos millones de pesetas a la víctima de la publicación no consentida de fotografías que mostraban el antes y el después de una cirugía de mamas que él le practicó. El Tribunal negó además el carácter científico de la publicación (que se hizo en un periódico).

Así pues, la doctrina concluye que en este evento, aplicable también a los casos de docencia, congresos y estudios estadísticos, la intimidad de la persona debe protegerse, garantizando su anonimato como regla absoluta y además, debe procurarse que la revelación interese a un público restringido (Fernández, 2002; Sánchez, 1998). Aquí, el médico debe tomar todas las medidas para que la identificación de las personas sea imposible de realizar (Welsch, 2003).
5. La concurrencia de un interés por parte del médico, es decir, la necesidad del profesional sanitario de defenderse de las acusaciones hechas en su contra dentro de un proceso de responsabilidad iniciado por su paciente, puede constituir otra hipótesis donde el profesional puede lícitamente descubrir el secreto médico. Sin embargo, dicha revelación debe hacerse con suma cautela, determinando la necesidad o no de dicha develación (Sánchez, 1998).

Por último, para el caso colombiano, la ley 23/1981 en su artículo 39,señala al médico el deber de velar porque sus auxiliares guarden la reserva profesional, pero dispone también que "no será responsable por la revelación que ellos hagan". Con relación a este aspecto, es oportuno recordar (Santos, 2007) que dicha exoneración va en contravía de lo consagrado por los artículos 1738 y 2347 del Código Civil, los cuales abren legalmente la posibilidad para que el médico sea declarado responsable por los hechos de sus dependientes o subordinados, por lo cual, se evidencia la notoria contradicción que respecto a estos postulados plantea el citado artículo 39 de la ley 23/1981.

\section{Sujetos obligados a mantener el secreto médico}

En principio se ha dicho que el médico es quien está obligado a mantener el secreto; empero, dada la complejidad de la medicina actual y su ejercicio en el ámbito hospitalario, se entiende que no solo es el facultativo sino un conjunto de distintas personas el que tiene fácil acceso al secreto. Por ejemplo, los colaboradores del médico, como las enfermeras, los auxiliares, los estudiantes o incluso otros doctores distintos al de cabecera. Todos estos sujetos deben guardar el secreto médico en aras de la defensa de la intimidad del paciente. En estos casos la reserva sigue existiendo, solo que su difusión a un grupo determinado de personas, hace que estas también estén obligadas a mantenerla.

Se está aquí ante lo que se conoce como secreto compartido o secret partagé como lo llama el 
legislador francés en la ley 303/2002 y como bien lo afirma Didier Truchet cuando sostiene que "le secret partagé (médecine de groupe, médecine hospitalière...) est un secret collective" (2013, p. 218).Desde esta figura, siempre que se guarden las debidas cautelas para la salvaguardia de la intimidad del paciente, a pesar de que el secreto sea conocido por distintos sujetos en el ámbito sanitario, no puede afirmarse incumplimiento de esta obligación.

Según la legislación francesa, el secreto compartido entre profesionales de la salud supone la satisfacción de dos condiciones. La primera, que la comunicación de la información tenga por objetivo asegurar la continuidad de la asistencia médica o hacerse cargo de los aspectos sanitarios de una mejor forma posible; la segunda, que el paciente no se haya opuesto a dicha revelación (Welsch, 2003).

\section{Sanciones al incumplimiento del deber de secreto médico}

Para terminar, como arriba se indicó, ante el incumplimiento de esta obligación de secreto profesional surgen consecuencias de carácter civil, disciplinario e incluso penal.

Las de carácter civil, relacionadas con la obligación de indemnizar los perjuicios causados por la infracción de dicho deber, tienen respaldo en el derecho común de la responsabilidad civil. Las de índole disciplinaria en los códigos y sanciones disciplinarias que tal falta pueda generar. En cuanto a las de naturaleza penal, en cambio, no existe unanimidad de regulaciones.

En efecto, las sanciones de carácter penal, en España, por ejemplo, el Código Penal castiga con triple pena (prisión, multa e inhabilitación para el ejercicio de la profesión), al médico que, desatendiendo su obligación de sigilo o reserva, divulgue a otra persona los secretos a los que tenga acceso (Such, 2013). Es el caso de un médico que fue condenado por el Tribunal Supremo a un año de prisión, multa, inhabilitación para el ejercicio de su profesión e indemnización igual a dos millones de pesetas por el hecho de divulgar a la madre de su paciente la realización de dos interrupciones legales de embarazo, las cuales había advertido al examinar la historia clínica de su paciente, quien había visitado al médico para una valoración neurológica. Igualmente, la normativa penal española sanciona con prisión y multa los casos de vulneración del secreto profesional por el uso de datos personales relativos a la salud de la persona y que han sido registrados en ficheros o soportes informáticos, electrónicos o telemáticos, o en cualquier otro tipo de archivo o registro público o privado.

El Código Penal francés, por su parte, condena también con prisión y multa, a los médicos, cirujanos y otros oficiales de la salud que revelen los secretos confiados, salvo los casos en que la ley los obliga y autoriza a denunciar.

En Colombia la violación del secreto médico no tiene los mismos alcances que en Francia y España, pues de acuerdo con el artículo 418 del Código Penal se sanciona al empleado público por la revelación de documento o noticia que deba mantenerse en privado; así pues, en nuestro país no cabría castigo de tipo penal, por ejemplo, para el médico que ejerce su actividad en el ámbito privado y viole su deber de secreto profesional.

\section{CONCLUSIÓN}

En el marco jurídico y en concreto en el de la responsabilidad, el médico como cualquier sujeto de derecho es titular de deberes y obligaciones. Dichas obligaciones y deberes se potencian cuando se vinculan con la práctica de una profesión, máxime cuando se trata del ejercicio médico.

El deber de información es uno de aquellos cuya infracción genera responsabilidad para el profesional sanitario. Se trata de un deber positivo (López, 2007), consistente en informar al paciente sobre su estado de salud, el tratamiento aconsejado, los riesgos de dicho tratamiento, las posibilidades de curación, entre otros. Es una responsabilidad que lleva implícito el deber de corresponder a la confianza que el paciente 
deposita en él y su cumplimiento debe permitir o estimular a quien la recibe una participación crítica en la decisión, favoreciendo la formulación de preguntas o la solicitud de aclaraciones en el marco de un diálogo realmente constructivo. Sin embargo, existen algunos eventos cuya caracterización hace deducir una excepción al cumplimiento de este deber y en consecuencia, una disminución o si se quiere, una exoneración de responsabilidad civil, todo lo cual, nos lleva a inferir que dicho deber no es absoluto, pues habrá que analizar cada caso concreto, antes de emitir un pronunciamiento sobre la responsabilidad u obligación de indemnizar los perjuicios causados al paciente por el incumplimiento al deber de información.

Por otra parte, la relación de confianza indispensable en el acto médico, asegura al paciente que lo que él le confía al profesional no será revelado. En efecto, el secreto médico se considera una obligación necesaria para garantizar el establecimiento de una relación de confianza entre el médico y el paciente, que permita un ejercicio de la medicina que asegure el respeto a la intimidad personal.

Este estado de cosas es obligatorio e incluso tácito, de tal modo que el enfermo no está obligado a formular de manera expresa al médico, su deseo de que este guarde la confidencialidad de la información que atañe a su vida privada y a su salud. El incumplimiento de este otro deber por parte del profesional médico involucra también su responsabilidad; no obstante, en la praxis, no es tan fácil desentrañar dicho quebrantamiento, debido a múltiples factores externos que en la actualidad, dada la manera como opera el ejercicio de la medicina, han influido en la estructuración de esta obligación. Así mismo, existen ciertos eventos que de una $\mathrm{u}$ otra forma permiten que el médico se exonere de esta obligación y que en consecuencia, no se afecte su responsabilidad, en tanto que se involucran aspectos donde la exigencia absoluta de la confidencialidad debe ceder frente a intereses de terceros, generales, colectivos o públicos, ante los cuales dicho deber ha de sacrificarse mediante una ponderación no siempre fácil de resolver.

\section{REFERENCIAS}

Bello, D. (2011). La responsabilidad médica. Bogotá:Pontificia Universidad Javeriana, Temis.

Bermúdez, M. (2000). La noción de la carga de la prueba y el régimen de la falla presunta en la responsabilidad de las entidades públicas prestadoras de los servicios médicos. Ponencia para el XXI Congreso Colombiano de Derecho Procesal (inédita). Cartagena de Indias.

Berthiau, D. (2007). Droit de la santé. París: Gualino Éditeur.

Bilancetti, M. (2003). La responsabilità penale e civile del medico. Padua: Cedam.

Blázquez, M.\& Molinos, J. (1997). Manual práctico de responsabilidad y defensa de la profesión médica (aspectos jurídicos y médico-forenses). Granada: Comares.

Criado, M. (1999). Aspectos médico-legales de la historia clínica. Madrid: Colex.

De Matteis, R. (2007). Responsabilità e servizi sanitari. Padua: Cedam.

Dorsner-Dolivet, A. (2006). La responsabilité du médecin. París: Economica.

Farneti, A. et al. (2007). Problemi di responsabilità sanitaria. Milán: Giuffrè.

Fernández, C. (2007). La relaciónjurídica del médico con elpaciente. Revista Prolegómenos. Derechos y Valores, X(20), 89-115.

Fernández, J. (2002). Sistema de responsabilidad médica. Granada: Comares.

Fernández, M. (2008). La responsabilidad médica. Problemas actuales. Bogotá: Ibáñez.

Fiori, A. (1999). Medicina legale della responsabilità medica. Milán: Giuffrè.

Fresa, R. (2008). La colpa professionale in ambito sanitario. Turín: Utet. 
Galán, J. (2011). Responsabilidad civil médica. Navarra: Aranzadi.

Ghersi, C.;Wingarten, C.; Iglesias, A.; Ferrari, G. \& Waisman, B. (1998). La relación médicopaciente en la responsabilidad civil. Medellín : Ágora Editores e Impresores Ltda.

Hocquet-Berg, S. \&Py, B. (2006). La responsabilité du médecin. París: Heures de France.

Jaramillo, C. (2008). Responsabilidad civil médica. La relación médico-paciente: análisis doctrinal y jurisprudencial. Bogotá:Pontificia Universidad Javeriana.

Jourdain, P. (1999). Nature de la responsabilité et portée des obligations du médecin. Responsabilité civile et assurances., Hors-Série, 7-8, 4-8.

Kimmel-Alcover, A. (1996). A propos des accidents médicaux: vers l'indemnisation de l'aléa thérapeutique?Petites Affiches,155, 17-24.

Lachica, E. (2002). El secreto médico y el consentimiento informado en los informes periciales. Cuadernos de Medicina Forense, 27, 29-37.

López, M. (2007). Teoría general de la responsabilidad civil médica en el derecho argentino y comparado. En M. López (ed.).Tratado de responsabilidad médica. Responsabilidad civil, penal y hospitalaria (pp. 1-389). Bogotá: Legis.

Lorenzetti, R. (2005). Responsabilidad civil de los médicos. Lima: Grijley.

Marcos, A. (2003). La double dimension de la faute en responsabilité médicale. Médecine.\&Droit., 59, 49-53.
Martín, J. (1998). Responsabilidad médica y derechos de los pacientes. Madrid: La Ley-Actualidad.

Mémeteau, G. (2010). Cours de droit médical. Burdeos: Les Études Hospitalières.

Mosset, J. \&Piedecasas, M. (2011). Derechos del paciente. Buenos Aires: Rubinzal-Culzoni Editores.

Sánchez, A. (1998). Contrato de servicios médicos y contrato de servicios hospitalarios. Madrid: Tecnos.

Santos, J. (2007). La responsabilidad civil médica en el derecho colombiano. En M. López (ed.).Tratado de responsabilidad médica. Responsabilidad civil, penal y hospitalaria (pp. 457-535). Bogotá: Legis.

Sargos, P. (2002). Évolution et mise en perspective de la jurisprudence de la Cour de cassation en matière de responsabilité civile des médecins. En Droit et économie de l'assurance et de la santé. Mélanges en l'honneur de Yvonne Lambert-Faivre et Denis-Clair Lambert (pp. 375-394). París: s.e.

Savatier, R. ; Auby, R. ; Savatier, J. ; \& Pequignot, H. (1956). Traité de droit médical. París: Librairies Techniques.

Such, J. (2013). El secreto profesional médico y la protección de datos. La responsabilidad médica en el ámbito administrativo. En M. Camas (ed.). Responsabilidad médica (pp. 215-315). Valencia: Tirant lo Blanch.

Truchet, D. (2013). Droit de la santé publique. París: Dalloz.

Welsch, S. (2003). Responsabilité du médecin. París: Litec. 